\title{
Defect Properties and Lithium Incorporation in $\mathrm{Li}_{2} \mathrm{ZrO}_{3}$
}

\author{
Kobiny Antony Rex ${ }^{1}$, Poobalasuntharam Iyngaran ${ }^{1}$, Navaratnarajah Kuganathan ${ }^{2,3, *(D)}$ \\ and Alexander Chroneos 2,3 (D) \\ 1 Department of Chemistry, University of Jaffna, Sir. Pon Ramanathan Road, \\ Thirunelvely, Jaffna 40000, Sri Lanka; antonyrexkobiny@gmail.com (K.A.R.); piyngs7@gmail.com (P.I.) \\ 2 Department of Materials, Imperial College London, London SW7 2AZ, UK; \\ alexander.chroneos@imperial.ac.uk or ab8104@coventry.ac.uk \\ 3 Faculty of Engineering, Environment and Computing, Coventry University, Priory Street, \\ Coventry CV1 5FB, UK \\ * Correspondence: n.kuganathan@imperial.ac.uk or ad0636@coventry.ac.uk
}

Citation: Rex, K.A.; Iyngaran, P.; Kuganathan, N.; Chroneos, A. Defect Properties and Lithium Incorporation in $\mathrm{Li}_{2} \mathrm{ZrO}_{3}$. Energies 2021, 14, 3963. https://doi.org/10.3390/ en14133963

Academic Editor: Carlos Miguel Costa

Received: 13 June 2021

Accepted: 30 June 2021

Published: 1 July 2021

Publisher's Note: MDPI stays neutral with regard to jurisdictional claims in published maps and institutional affiliations.

Copyright: (c) 2021 by the authors. Licensee MDPI, Basel, Switzerland. This article is an open access article distributed under the terms and conditions of the Creative Commons Attribution (CC BY) license (https:// creativecommons.org/licenses/by/ $4.0 /)$.

\begin{abstract}
Lithium zirconate is a candidate material in the design of electrochemical devices and tritium breeding blankets. Here we employ an atomistic simulation based on the classical pair-wise potentials to examine the defect energetics, diffusion of Li-ions, and solution of dopants. The LiFrenkel is the lowest defect energy process. The Li-Zr anti-site defect cluster energy is slightly higher than the Li-Frenkel. The Li-ion diffuses along the $\mathrm{c}$ axis with an activation energy of $0.55 \mathrm{eV}$ agreeing with experimental values. The most favorable isovalent dopants on the $\mathrm{Li}$ and $\mathrm{Zr}$ sites were $\mathrm{Na}$ and Ti respectively. The formation of additional $\mathrm{Li}$ in this material can be processed by doping of $\mathrm{Ga}$ on the $\mathrm{Zr}$ site. Incorporation of Li was studied using density functional theory simulation. $\mathrm{Li}$ incorporation is exoergic with respect to isolated gas phase Li. Furthermore, the semiconducting nature of LZO turns metallic upon Li incorporation.
\end{abstract}

Keywords: $\mathrm{Li}_{2} \mathrm{ZrO}_{3}$; defects; diffusion; dopants; DFT; classical simulation

\section{Introduction}

Lithium zirconate $\left(\mathrm{Li}_{2} \mathrm{ZrO}_{3}\right.$ or $\left.\mathrm{LZO}\right)$ is a material of interest for many applications including electrode or electrolyte in Li-ion batteries [1-3], breeder blanket in nuclear reactors [4-6] and sorbent capture of $\mathrm{CO}_{2}$ [7-9] due to its chemical and thermal stability. For battery applications, Li-ion conductivity should be high as battery performance is partly dependent on it during the charge-discharge process. Experimental work based on nuclear magnetic resonance (NMR) spectroscopy shows that the Li-ion conductivity in this material is high and the activation energy is calculated to be $\sim 0.51-0.65 \mathrm{eV}$ [10]. Xu et al. [11] reported that the rate performance of $\mathrm{LiNi}_{0.5} \mathrm{Co}_{0.2} \mathrm{Mn}_{0.3} \mathrm{O}_{2}$ can be improved by the surface coating of LZO. Electrochemical performance of LZO was examined experimentally and an excellent cyclic performance and rate capability reported [1]. In a density functional theory (DFT) simulation by Ferreira et al. [12], the relevance of vacancy-assisted Li-ion migration has been discussed.

Defects and dopants can influence a material's electrochemical property as diffusion of ions is directly related to the concentration of point defects $[13,14]$. Particularly, introducing dopants is a common way to form hyperstoichiometric dopant concentration of oxygen vacancies or interstitials, which in turn can impact oxygen self-diffusion as they effectively are the migrating defects [15]. Additionally, dopants can impact the migration energy barriers. In recent work, Kordatos et al. [16] performed DFT simulations to show that doping of aliovalent and isovalent cations on the $\mathrm{Zr}$ site is an efficient way to form oxygen vacancies and improve the diffusion and electronic properties of LZO. In the present study, atomistic simulations based on the classical pair-wise potentials to examine the defects, dopants and diffusion of Li-ions in LZO. In particular, we studied isovalent dopants on 
the $\mathrm{Li}$ and $\mathrm{Zr}$ sites for stabilizing $\mathrm{LZO}$ and aliovalent dopants on the $\mathrm{Zr}$ site for creating additional Li in LZO. In order to examine the incorporation, we used DFT simulations.

\section{Computational Methods}

Classical atomistic simulation was performed to calculate the defect energies, Li-ion migration pathways and solution energies for a variety of dopants. The generalized utilized lattice program (GULP) [17] was used. This method is based on the short-range (repulsive Pauli and attractive van der Waals) and long range (Coulombic) ionic interactions between ions. Short range interactions were modelled using Buckingham potentials (refer to Table 1) [18-20]. This potential method allows two unbonded atoms to interact and models the short-range interaction as a function of the intermolecular distance between those atoms. The Mott-Littleton method [21] was used to model point defects and migrating ions. In this method, the crystal surrounding the defect is divided into two regions (region I and region II). In region I, forces exerted by the defects are strong. Therefore, the ions in this region are relaxed explicitly. As forces in region II are relatively weak, quasi-continuum methods are used to relax the ions. Polarization of ions was modelled with the core-shell approach. In previous work, we reported the methodology of calculating migration pathways and activation energies of migration in detail [22-24].

Table 1. Buckingham potential parameters used [18-20].

\begin{tabular}{cccccc}
\hline Interaction & $A / \mathbf{e V}$ & $\rho / \AA$ & $C / \mathbf{e V} \cdot \AA^{6}$ & $\mathbf{Y} / \mathbf{e}$ & $\mathbf{K} / \mathbf{e V} \cdot \AA^{-2}$ \\
\hline $\mathrm{Li}^{+}-\mathrm{O}^{2-}$ & 632.1018 & 0.2906 & 0.00 & 1.00 & 99,999 \\
\hline $\mathrm{Zr}^{4+}-\mathrm{O}^{2-}$ & 1502.11 & 0.3477 & 5.10 & 1.35 & 169.617 \\
\hline $\mathrm{O}^{2-}-\mathrm{O}^{2-}$ & $22,764.0$ & 0.1490 & 43.0 & -2.80 & 31.0 \\
\hline
\end{tabular}

Two-body $\left[\Phi_{i j}\left(r_{i j}\right)=A_{i j} \exp \left(-r_{i j} / \rho_{i j}\right)-C_{i j} / r_{i j}{ }^{6}\right.$, where A, $\rho$ and $\mathrm{C}$ are parameters. The values of $Y$ and $\mathrm{K}$ represent the shell charges and spring constants.

Incorporation of Li was studied using DFT simulation as implemented in the Vienna ab initio simulation program (VASP) code [25]. This code is based on projected augmented wave (PAW) potentials [26] and plane wave basis sets. We used a plane wave basis set with a cut-off of $500 \mathrm{eV}$ in all calculations. For bulk LZO, we used $4 \times 8 \times 4$ Monkhorst-Pack [27] $k$-points. A regular grid of k-points are distributed homogeneously in the Brillouin zone and sampled in the Monkhorst-Pack method. Reciprocal unit cell is first converted from the real space and the k-points are sampled based on the reciprocal basis vectors. A $2 \times 2$ $\times 2$ super cell containing 192 atoms was used to model Li incorporation. For this supercell, $2 \times 4 \times 2$ Monkhorst-Pack $k$-points were used. The generalized gradient approximation (GGA) parameterized by Perdew, Burke, and Ernzerhof (PBE) [28] was used to model exchange correlation. The conjugate gradient algorithm [29] was used to relax both atomic positions and cell parameters. Short range temporary dispersive interactions were modelled using zero damping DFT + D3 as parameterized by Grimme et al [30].

\section{Results and Discussion}

\subsection{Structure of $L Z O$}

$\mathrm{Li}_{2} \mathrm{ZrO}_{3}$ exhibits a monoclinic crystallographic structure with space group of $\mathrm{C} 2 / \mathrm{c}$ (no. 15). Heiba et al. [31] reported the crystal structure of $\mathrm{LZO}$ with experimental values are $\mathrm{a}=5.4089 \AA, \mathrm{b}=9.0309 \AA, \mathrm{c}=5.4144 \AA, \alpha=\gamma=90^{\circ}$ and $\beta=112.50^{\circ}$. The crystal structure has $\mathrm{ZrO}_{6}$ octahedral units, which are interconnected by sharing their edges and corners (see Figure 1). Buckingham potentials used in the classical simulation and PAW potentials utilized in the DFT simulation were validated by performing geometry optimization calculations and comparing the relaxed lattice parameters with corresponding experimental values. There is a reasonable agreement between simulations and the experiment (refer to Table 2) as explained by Oberkampf et al. [32] 


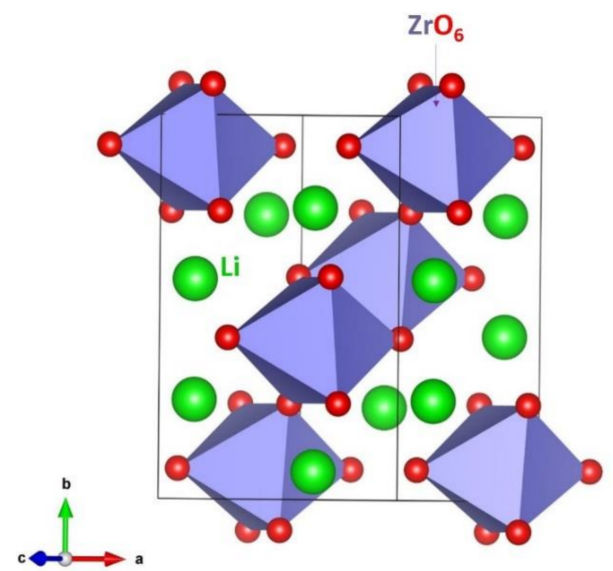

Figure 1. Monoclinic crystal structure of LZO.

Table 2. Calculated and experimental lattice parameters of monoclinic LZO.

\begin{tabular}{|c|c|c|c|c|c|}
\hline \multirow{2}{*}{ Parameter } & \multicolumn{2}{|c|}{ Calculated } & \multirow{2}{*}{$\begin{array}{c}\text { Experiment } \\
{[31]}\end{array}$} & \multicolumn{2}{|c|}{$|\Delta|(\%)$} \\
\hline & Force Field & DFT & & Force Field & DFT \\
\hline a $(\AA)$ & 5.5912 & 5.3411 & 5.4089 & 3.37 & 1.25 \\
\hline $\mathrm{b}(\AA)$ & 8.8458 & 9.0737 & 9.0309 & 2.05 & 0.47 \\
\hline$c(\AA)$ & 5.4787 & 5.3874 & 5.4144 & 1.19 & 0.50 \\
\hline$\alpha=\gamma\left({ }^{\circ}\right)$ & 90.00 & 90.00 & 90.00 & 0.00 & 0.00 \\
\hline$\beta\left(^{\circ}\right)$ & 115.66 & 111.38 & 112.50 & 2.81 & 0.99 \\
\hline $\mathrm{V}\left(\AA^{3}\right)$ & 244.25 & 243.12 & 244.35 & 0.04 & 0.50 \\
\hline
\end{tabular}

\subsection{Defect Energetics}

In this section, we calculate the formation energies of point defects (vacancies and interstitials) using a classical simulation. Frenkel and Schottky defect energies were then calculated by combining point defect energies and appropriate lattice energies. Anti-site defects were also calculated. This defect is important as it can influence the diffusion property of a material. The following reaction equations were constructed to describe the intrinsic defect processes using the Kröger-Vink notation [33].

$$
\begin{gathered}
\text { Li Frenkel : } \mathrm{Li}_{\mathrm{Li}}^{\mathrm{X}} \rightarrow V_{\mathrm{Li}}^{\prime}+\mathrm{Li}_{\mathrm{i}}^{\bullet} \\
\text { Zr Frenkel : } \mathrm{Zr}_{\mathrm{Zr}}^{\mathrm{X}} \rightarrow V_{\mathrm{Zr}}^{\prime \prime \prime \prime}+\mathrm{Zr}_{\mathrm{i}}^{\bullet \bullet \bullet \bullet} \\
\text { O Frenkel : } \mathrm{O}_{\mathrm{O}}^{\mathrm{X}} \rightarrow V_{\mathrm{O}}^{\bullet \bullet}+\mathrm{O}_{\mathrm{i}}^{\prime \prime} \\
\text { Schottky : } 2 \mathrm{Li}_{\mathrm{Li}}^{\mathrm{X}}+\mathrm{Zr}_{\mathrm{Zr}}^{\mathrm{X}}+3 \mathrm{O}_{\mathrm{O}}^{\mathrm{X}} \rightarrow 2 V_{\mathrm{Li}}^{\prime \prime}+V_{\mathrm{Zr}}^{\prime \prime \prime \prime}+3 V_{\mathrm{O}}^{\bullet \bullet}+\mathrm{Li}_{2} \mathrm{ZrO}_{3} \\
\mathrm{Li}_{2} \mathrm{O} \text { Schottky }: 2 \mathrm{Li}_{\mathrm{Li}}^{\mathrm{X}}+\mathrm{O}_{\mathrm{O}}^{\mathrm{X}} \rightarrow 2 V_{\mathrm{Li}}^{\prime \prime}+V_{\mathrm{O}}^{\bullet \bullet}+\mathrm{Li}_{2} \mathrm{O} \\
\mathrm{ZrO}_{2} \text { Schottky : } \mathrm{Zr}_{\mathrm{Zr}}^{\mathrm{X}}+2 \mathrm{O}_{\mathrm{O}}^{\mathrm{X}} \rightarrow V_{\mathrm{Zr}}^{\prime \prime \prime \prime}+2 V_{\mathrm{O}}^{\bullet \bullet}+\mathrm{ZrO}_{2} \\
\mathrm{Li} / \mathrm{Zr} \text { antisite (isolated) }: \mathrm{Li}_{\mathrm{Li}}^{\mathrm{X}}+\mathrm{Zr}_{\mathrm{Zr}}^{\mathrm{X}} \rightarrow \mathrm{Li}_{\mathrm{Zr}}^{\prime \prime \prime}+\mathrm{Zr}_{\mathrm{Li}}^{\bullet \bullet \bullet} \\
\mathrm{Li} / \mathrm{Zr} \text { antisite (cluster) }: \mathrm{Li}_{\mathrm{Li}}^{\mathrm{X}}+\mathrm{Zr}_{\mathrm{Zr}}^{\mathrm{X}} \rightarrow\left\{\mathrm{Li}_{\mathrm{Zr}}^{\prime \prime \prime}+\mathrm{Zr}_{\mathrm{Li}}^{\bullet \bullet \bullet}\right\}
\end{gathered}
$$

The defect energies are tabulated in Table 3. The lowest defect formation energy is calculated for the Li Frenkel (1.09 eV/defect) as reported in a previous DFT simulation [13]. The Li-Zr anti-site cluster defect energy is higher only by $0.37 \mathrm{eV}$ compared with the LiFrenkel. In this defect, a small amount of $\mathrm{Li}$ and $\mathrm{Zr}$ atoms would exchange their positions simultaneously. However, this defect process would not take place spontaneously and 
would be dependent on the temperature and synthetic conditions. The difference in energy between the isolated and cluster forms of the anti-site defect is the binding energy. Here, the binding energy is calculated to be $-1.42 \mathrm{eV}$. The presence of the anti-site defect has been reported in many experimental and theoretical studies [34-36]. This means isolated defects form clusters without any energy penalty. The $\mathrm{Li}_{2} \mathrm{O}$ Schottky defect is the lowest energy process among other Schottky processes. The formation of $\mathrm{Li}_{2} \mathrm{O}$ can destabilize the lattice. Such a destabilization can degrade the battery performance. The $\mathrm{Zr}$ Frenkel is higher in energy (by $3.59 \mathrm{eV}$ ) than the $\mathrm{O}$ Frenkel. This is due to the high formation energy of introducing $\mathrm{Zr}$ vacancy with +4 charge.

Table 3. Defect formation energies of intrinsic defect process calculated in monoclinic LZO.

\begin{tabular}{cccc}
\hline Defect Process & $\begin{array}{c}\text { Equation } \\
\text { Number }\end{array}$ & $\begin{array}{c}\text { Defect Energy } \\
(\mathbf{e V})\end{array}$ & $\begin{array}{c}\text { Defect Energy } \\
(\mathbf{e V}) / \text { Defect }\end{array}$ \\
\hline $\mathrm{Li}$ Frenkel & $(1)$ & 2.18 & 1.09 \\
\hline $\mathrm{Zr}$ Frenkel & $(2)$ & 13.64 & 6.82 \\
\hline O Frenkel & $(3)$ & 6.46 & 3.23 \\
\hline Schottky & $(4)$ & 14.6 & 2.45 \\
\hline $\mathrm{Li}_{2} \mathrm{O}$ Schottky & $(5)$ & 6.74 & 2.25 \\
\hline $\mathrm{ZrO}$ Schottky & $(6)$ & 9.97 & 3.32 \\
\hline $\mathrm{Li}-\mathrm{Zr}$ anti-site (isolated) & $(7)$ & 5.76 & 2.88 \\
\hline $\mathrm{Li}-\mathrm{Zr}$ anti-site (cluster) & $(8)$ & 2.92 & 1.46 \\
\hline
\end{tabular}

\subsection{Diffusion of Li-Ions}

Here, we discuss the diffusion of Li-ions and their activation energies. Classical atomistic simulations [37] were used to examine the Li-ion diffusion pathways and migration energies. Diffusion property of a materials is partly important in constructing a promising Li-ion battery. The identification of the diffusion ion pathways through experimental investigation is often challenging. Computational modelling has been shown to be a powerful tool to determine the migration pathways and activation energies [38-40]. Five different local Li hops (A-E) were identified, as shown in Figure 2. In Table 4, we report the Li hop distances and activation energies. Figure 3 shows the energy profile diagrams plotted for Li hops.

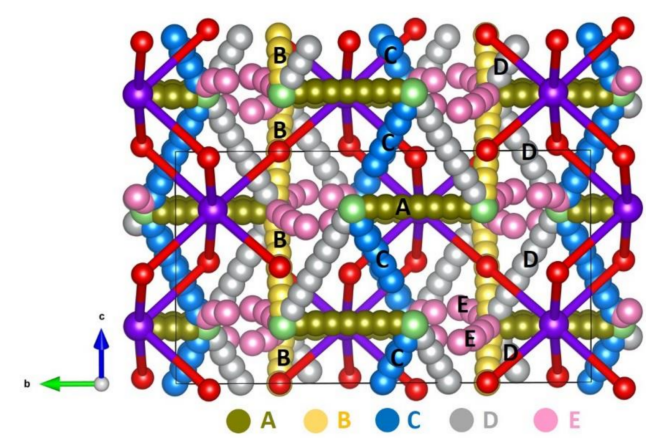

Figure 2. Li-ion diffusion pathways. Green, yellow, blue, grey and pink color atoms correspond to different Li hops. 
Table 4. Li hop distances and their activation energies as shown in Figure 2.

\begin{tabular}{ccc}
\hline Diffusion Path & Li-Li Separation $(\AA)$ & Activation Energy (eV) \\
\hline A & 2.78 & 0.65 \\
\hline B & 2.95 & 0.63 \\
\hline C & 3.02 & 0.55 \\
\hline D & 3.12 & 0.96 \\
\hline E & 3.24 & 1.23 \\
\hline
\end{tabular}
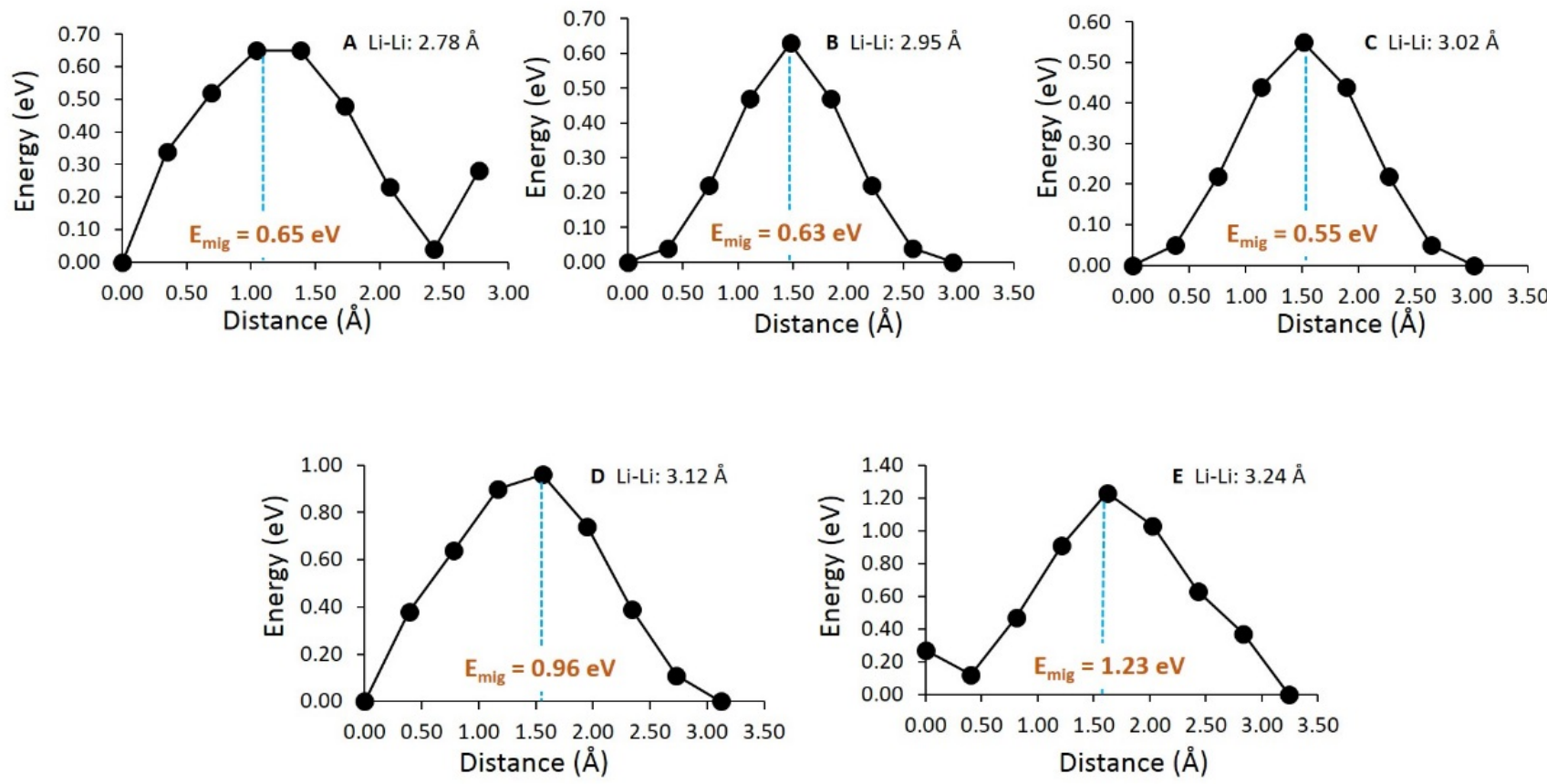

Figure 3. Energy profile diagrams for local Li hop activation energies. Letters (A-E) are local Li hops as shown in Figure 2.

The hop $\mathrm{C}$ exhibits the lowest activation energy. A long range diffusion pathway $(\mathrm{C} \rightarrow \mathrm{C} \rightarrow \mathrm{C} \rightarrow \mathrm{C})$ consisting of hop $\mathrm{C}$ was constructed. This pathway has a pattern of zig-zag and Li-ion moves in the $b c$ plane (see Figure 2). The difference in the activation energies calculated for hops $\mathrm{A}(0.65 \mathrm{eV})$ and $\mathrm{B}(0.63 \mathrm{eV})$ is very small. While there is a long range diffusion possible for hop $\mathrm{B}(\mathrm{B} \rightarrow \mathrm{B} \rightarrow \mathrm{B} \rightarrow \mathrm{B})$ in the $a c$ plane with an overall activation energy of $0.63 \mathrm{eV}$, the diffusion of hop $\mathrm{A}$ is limited along the $b$ axis. Another possible long range diffusion pathway $(\mathrm{D} \rightarrow \mathrm{D} \rightarrow \mathrm{D} \rightarrow \mathrm{D})$ can be constructed by connecting local hops $\mathrm{D}$ in the $b c$ plane. However, its activation energy is higher by $0.41 \mathrm{eV}$ than that calculated for the lowest migration pathway $(\mathrm{C} \rightarrow \mathrm{C} \rightarrow \mathrm{C} \rightarrow \mathrm{C})$. Finally, hops $\mathrm{E}$ were connected. In this long range diffusion $(\mathrm{E} \rightarrow \mathrm{E} \rightarrow \mathrm{E} \rightarrow \mathrm{E})$, activation energy is relatively high. In a Li-NMR study carried out by Baklanova et al. [10], the activation energy for Li-ion migration was estimated to be $0.50-0.65 \mathrm{eV}$. This is in good agreement with the values calculated in this study. In a DFT simulation by Ferreira [12], a range of activation energies were reported with respect to reactants and products. Activation energies calculated from the products and reactants in the vacancy-assisted Li-ion diffusion are $0.651 \mathrm{eV}$ and $0.749 \mathrm{eV}$ respectively [12]. These values agree with those reported in this study, although DFT simulations treated Li vacancies as neutral in contrast to the current simulation where all defects were modelled as fully charged ions.

\subsection{Solution of Dopants}

Modification of material properties can be achieved through cation doping. In this strategy, isovalent doping requires no charge-compensating defect, whereas aliovalent 
doping can introduce point defects (vacancies and interstitials) in the lattice. The degree of disorder of a material is influenced by the concentration of point defects. Furthermore, point defect concentration increases exponentially with an increasing temperature [41]. Here we examined a variety of dopant ions using classical simulation. Table S1 in the Supplementary reports the Buckingham potentials used for dopants in this study (see Table S1).

\subsubsection{Isovalent Dopants}

First, doping of isovalent dopants $(\mathrm{M}=\mathrm{Na}, \mathrm{K}$ and $\mathrm{Rb})$ on the $\mathrm{Li}$ site was considered as explained by the following reaction equation:

$$
\mathrm{M}_{2} \mathrm{O}+\mathrm{Li}_{\mathrm{Li}}^{\mathrm{X}} \rightarrow 2 \mathrm{M}_{\mathrm{Li}}^{\mathrm{X}}+\mathrm{Li}_{2} \mathrm{O}
$$

Figure 4a reports the solution energies with respect to the radii of the dopant ions. Exothermic solution energy of $-0.10 \mathrm{eV}$ is calculated for $\mathrm{Na}^{+}$. The $\mathrm{Li}^{+}$has an ionic radius of $0.76 \AA$. The favorability of $\mathrm{Na}^{+}$can be partly due to its ionic radius (1.02 $\AA$ ), closer to that of $\mathrm{Li}^{+}$. Solution energies are positive for both $\mathrm{K}^{+}$and $\mathrm{Rb}^{+}$. The highest solution of energy of $4.98 \mathrm{eV}$ is calculated for $\mathrm{Rb}^{+}$, meaning that this dopant is highly unlikely for the doping process under normal temperatures.

(a)

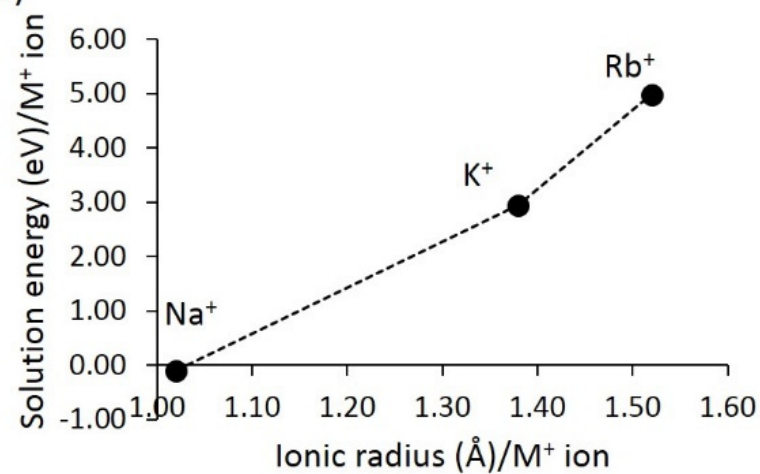

(b)

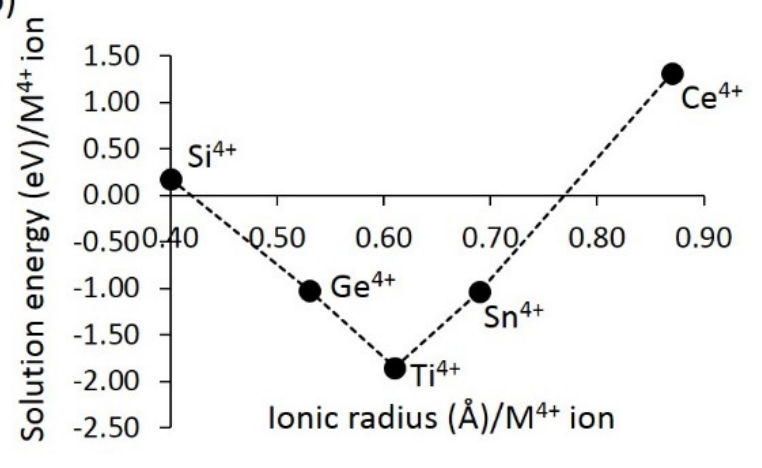

Figure 4. Solution energies calculated for (a) $\mathrm{M}_{2} \mathrm{O}(\mathrm{M}=\mathrm{Na}, \mathrm{K}$ and $\mathrm{Rb})$ and $(\mathbf{b}) \mathrm{MO}_{2}(\mathrm{M}=\mathrm{Si}, \mathrm{Ge}, \mathrm{Ti}, \mathrm{Sn}$ and $\mathrm{Ce})$.

Next, tetravalent dopants $(\mathrm{M}=\mathrm{Si}, \mathrm{Ge}, \mathrm{Ti}, \mathrm{Sn}$ and $\mathrm{Ce})$ were considered for doping on the $\mathrm{Zr}$ site. The following reaction equation describes the doping process.

$$
\mathrm{MO}_{2}+\mathrm{Zr}_{\mathrm{Zr}}^{\mathrm{X}} \rightarrow \mathrm{M}_{\mathrm{Zr}}^{\mathrm{X}}+\mathrm{ZrO}_{2}
$$

Exothermic solution energies are calculated for $\mathrm{Ge}^{4+}, \mathrm{Ti}^{4+}$ and $\mathrm{Sn}^{4+}$. The most favorable dopant is the $\mathrm{Ti}^{4+}$ with a solution energy of $-1.85 \mathrm{eV}$. Solution energy for $\mathrm{Si}^{4+}$ is $0.18 \mathrm{eV}$. The endoergic solution energy for this dopant is owing to the ionic radius of $\mathrm{Si}^{4+}$ $(0.40 \AA)$ deviating much from that of $\mathrm{Zr}^{4+}(0.72 \AA)$. The $\mathrm{Ce}^{4+}$ exhibits the largest solution energy of $1.31 \mathrm{eV}$.

\subsubsection{Aliovalent Dopants}

The formation of extra $\mathrm{Li}^{+}$ions in $\mathrm{LZO}$ can be of interest to enhance the capacity of LZO for both battery and nuclear applications. Doping of trivalent cations (Al, Ga, Sc, In, $\mathrm{Y}, \mathrm{Gd}$, and $\mathrm{La}$ ) was considered on the $\mathrm{Zr}$ site. This doping process will create $\mathrm{Li}$ interstitials based on the following reaction equation:

$$
\mathrm{M}_{2} \mathrm{O}_{3}+2 \mathrm{Zr}_{\mathrm{Zr}}^{\mathrm{X}}+\mathrm{Li}_{2} \mathrm{O} \rightarrow 2 \mathrm{M}_{\mathrm{Zr}}^{\prime}+2 \mathrm{Li}_{\mathrm{i}}^{\bullet}+2 \mathrm{ZrO}_{2}
$$

Ga is the promising dopant for this process (refer to Figure 5). Solution energies calculated for Sc and In are higher only by $0.09 \mathrm{eV}$ and $0.19 \mathrm{eV}$ respectively compared 
with that calculated for Ga. The dopant $\mathrm{Al}$ has a solution energy of $2.09 \mathrm{eV}$. There is an increase in the solution energy with an ionic radius from Ga to La. The highest solution energy calculated for La indicates that this dopant is an unfavorable dopant under normal conditions. The possible doped configuration that can be prepared by the experiments is $\mathrm{Li}_{2+\mathrm{x}} \mathrm{Ga}_{\mathrm{x}} \mathrm{Zr}_{1-\mathrm{x}} \mathrm{O}_{3}(\mathrm{x}=0.0-1.0)$.

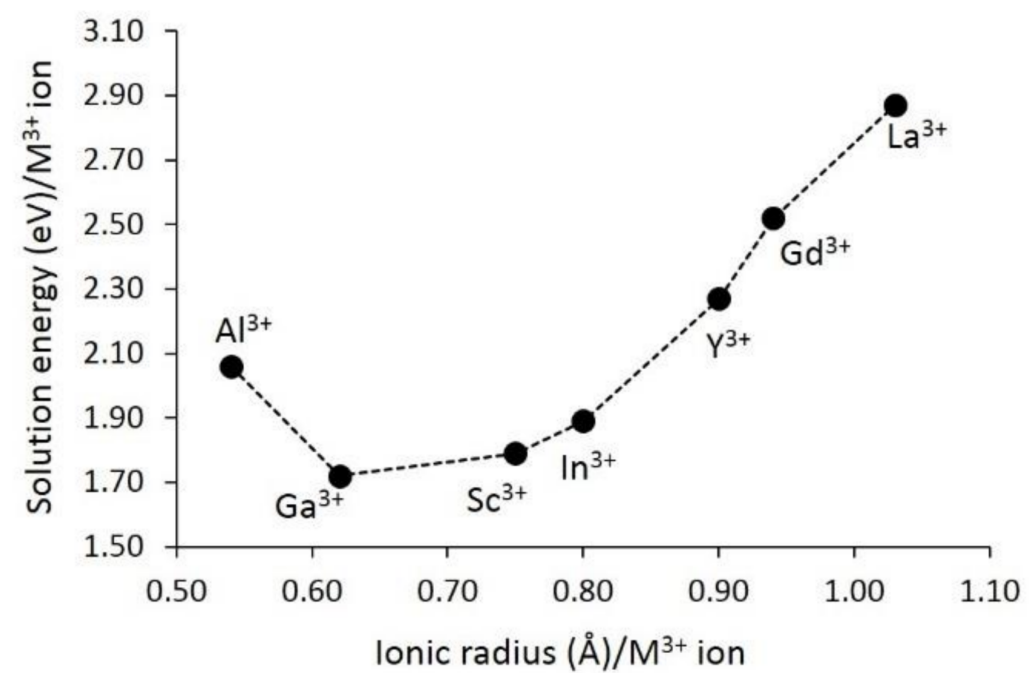

Figure 5. Solution energies calculated for $\mathrm{M}_{2} \mathrm{O}_{3}(\mathrm{M}=\mathrm{Al}, \mathrm{Ga}, \mathrm{Sc}, \mathrm{In}, \mathrm{Y}, \mathrm{Gd}$, and La) on the $\mathrm{Zr}$ site with respect to the $\mathrm{M}^{3+}$ ionic radius.

\subsection{Li Incorporation in LZO}

Simulations based on DFT were employed to examine the Li incorporated geometries and their electronic structures. Calculated total density of states (DOS) plot of bulk LZO is shown in Figure 6. Previous DFT simulation by Duan [42] shows that LZO is a wide gap semiconductor (band gap of $3.90 \mathrm{eV}$ ) which is in agreement with the calculated band gap of $3.60 \mathrm{eV}$ in this study (see Figure 6). The net magnetic moment of the relaxed structure of bulk LZO is zero, as evidenced by the total DOS plot where spin-up states are the mirror image of spin-down states about the $x$-axis.

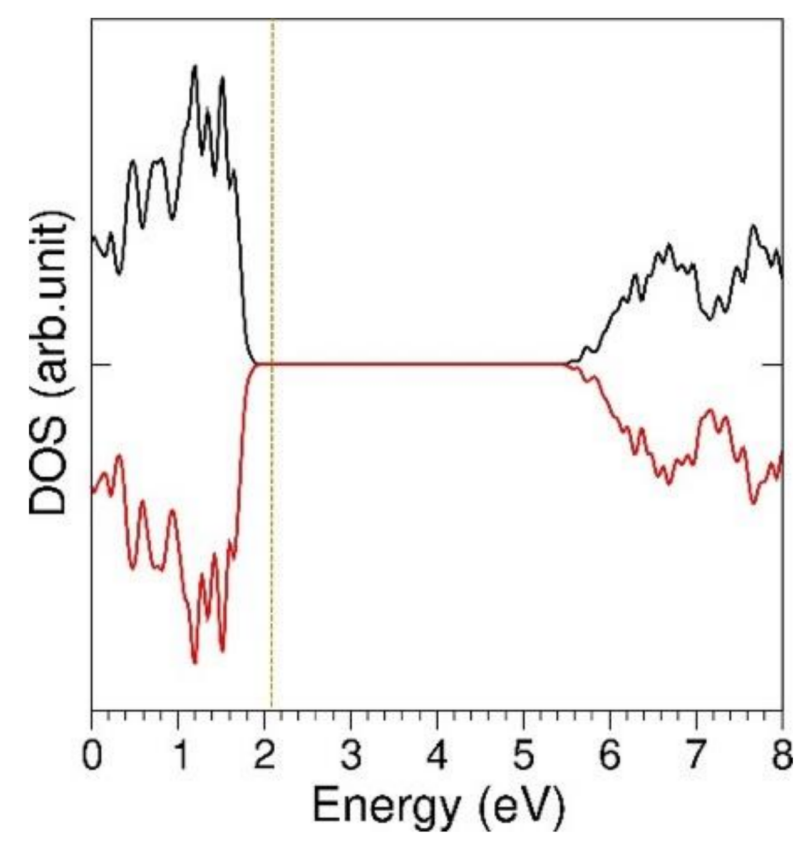

Figure 6. Total DOS plot of LZO. Vertical dot line corresponds to the Fermi energy level. 
We have subsequently incorporated four Li atoms. Relaxed structures are shown in Figure 7. Incorporation is exoergic with respect to gas-phase Li atoms and endoergic with respect to Li metal (see Table 5). This is because of the higher endoergic dissociation energy to form $\mathrm{Li}$ atoms from bulk $\mathrm{Li}$ than the exoergic incorporation energy of gaseous $\mathrm{Li}$ atoms. The first two Li atom incorporation is highly negative compared with that of the third and fourth. Bader charge analysis [43] shows that Li atoms are positively charged and form strong bonds with oxygen in the lattice. Bader charge analysis uses partitioning method to calculate electronic charges on individual atoms in the lattice. Using Zero flux surfaces, atoms are divided and charge density is partitioned. There is a gradual increase in volume upon each Li incorporation.
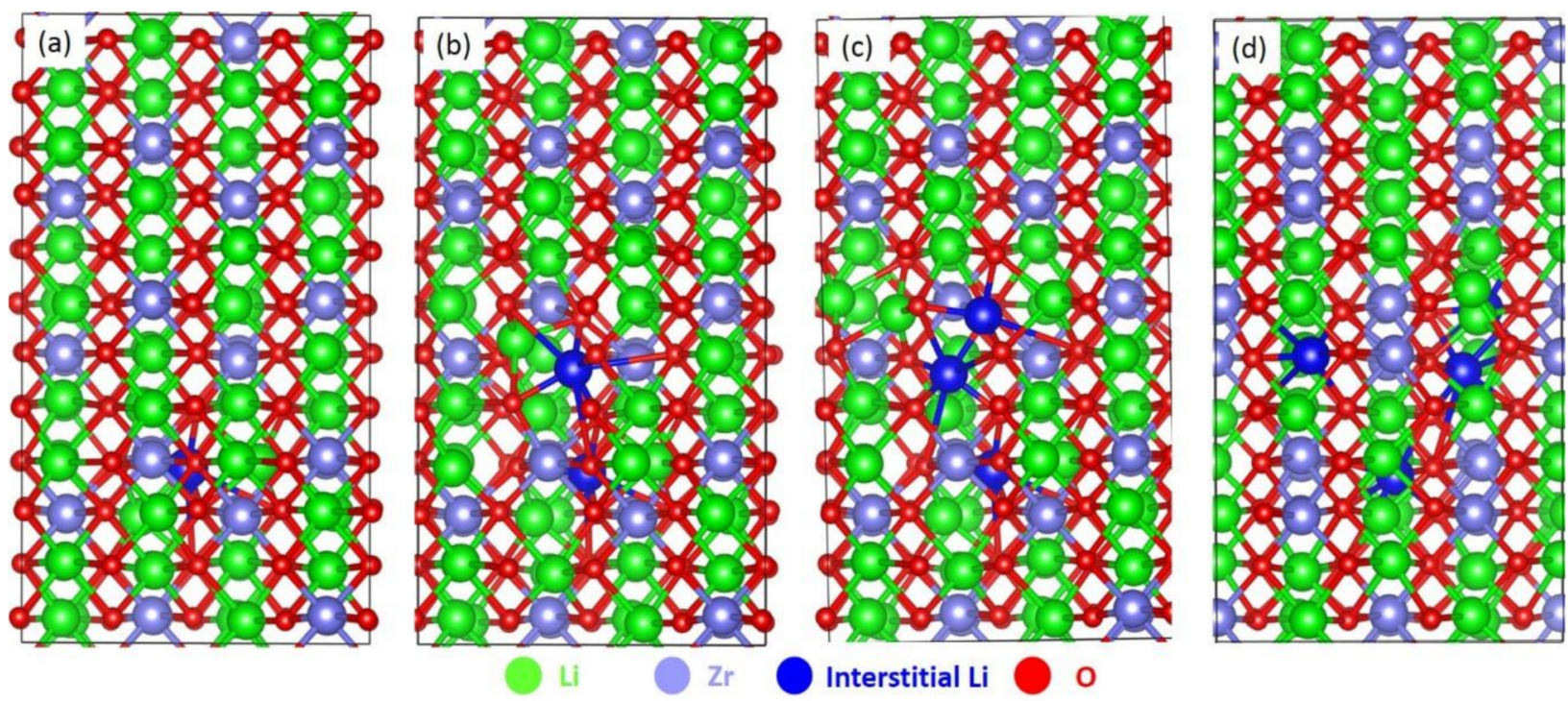

Figure 7. Relaxed structures of (a) a single Li, (b) 2Li, (c) 3Li and (d) $4 \mathrm{Li}$ incorporated in LZO.

Table 5. Calculated energies to incorporate $\mathrm{Li}$ atoms into LZO, Bader charges on the $\mathrm{Li}$ atoms and volume expansion upon successive incorporation.

\begin{tabular}{cccc}
\hline \multicolumn{1}{c}{ Reaction } & $\begin{array}{c}\text { Incorporation } \\
\text { Energy (eV) }\end{array}$ & $\begin{array}{c}\text { Bader Charge } \\
(\text { l e l) }\end{array}$ & $\Delta \mathbf{V ~ ( \% ) ~}$ \\
\hline $\mathrm{Li}+\mathrm{Li}_{2} \mathrm{ZrO}_{3} \rightarrow \mathrm{Li}_{\mathrm{Li}} \mathrm{ZrO}_{3}$ & $-1.15 \mathrm{eV}(0.52 \mathrm{eV})$ & +1.00 & 1.21 \\
\hline $\mathrm{Li}+\mathrm{Li} . \mathrm{Li}_{2} \mathrm{ZrO}_{3} \rightarrow 2 \mathrm{Li} . \mathrm{Li}_{2} \mathrm{ZrO}_{3}$ & $-1.12 \mathrm{eV}(0.55 \mathrm{eV})$ & $+1.00(2)$ & 2.16 \\
\hline $\mathrm{Li}+2 \mathrm{Li} . \mathrm{Li}_{2} \mathrm{ZrO}_{3} \rightarrow 3 \mathrm{Li} . \mathrm{Li}_{2} \mathrm{ZrO}_{3}$ & $-0.60 \mathrm{eV}(1.07 \mathrm{eV})$ & $+1.00(3)$ & 2.37 \\
\hline $\mathrm{Li}+3 \mathrm{Li} . \mathrm{Li}_{2} \mathrm{ZrO}_{3} \rightarrow 4 \mathrm{Li} . \mathrm{Li}_{2} \mathrm{ZrO}_{3}$ & $-0.85 \mathrm{eV}(0.82 \mathrm{eV})$ & $+1.00(4)$ & 2.73 \\
\hline
\end{tabular}

Calculated total DOS plots of Li-incorporated structures are shown in Figure 8. Incorporation shifts the Fermi level towards the conduction band. This is because of an additional electron created by each Li incorporation. In all cases, Fermi level is occupied by states associated with $\mathrm{Li}$ and the resultant composites became metallic. 

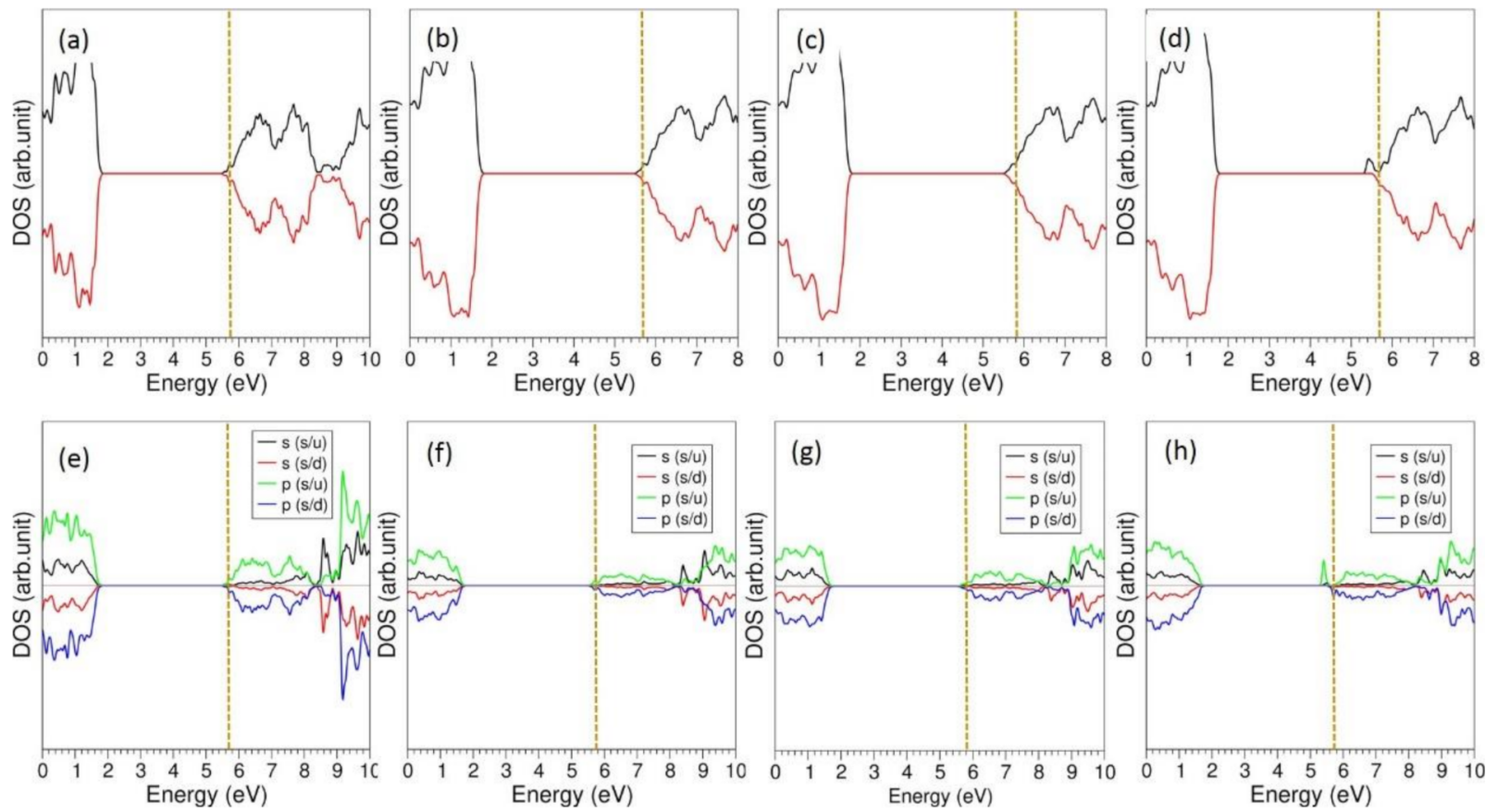

Figure 8. Total DOS plots of (a) a single $\mathrm{Li},(\mathbf{b}) 2 \mathrm{Li}$, (c) $3 \mathrm{Li}$ and (d) $4 \mathrm{Li}$ incorporated in $\mathrm{Li}_{2} \mathrm{ZrO}_{3}$. Corresponding $\mathrm{Li}$ atomic DOS plots (e-h) are also shown.

\section{Summary}

Defect properties, diffusion of Li-ion, solution of dopants and Li incorporation were investigated using classical and DFT simulations. Calculations find that the dominant defect in this material is the Li-Frenkel, ensuring the formation of $\mathrm{Li}$ vacancies. The next most favorable defect is the $\mathrm{Li}-\mathrm{Zr}$ anti-site defect cluster. Li-ion diffusion is noted along the $\mathrm{c}$ axis and its activation energy is $0.55 \mathrm{eV}$. The isovalent dopants on the $\mathrm{Li}$ and $\mathrm{Zr}$ are calculated to be the $\mathrm{Na}$ and Ti respectively. The promising dopant on the $\mathrm{Zr}$ site to create extra $\mathrm{Li}$ in the lattice is Ga. DFT simulations show that incorporation of $\mathrm{Li}$ is exoergic with respect to gas phase $\mathrm{Li}$. The metallic nature of the resultant composite is confirmed by the formation of $\mathrm{Li}^{+}$ions and electrons in the lattice. The results reported in this study can be validated by experiments for the development of Li-ion batteries and tritium breeding blankets.

Supplementary Materials: The following are available online at https:/ /www.mdpi.com/article/10 $.3390 /$ en14133963/s1. Table S1. Interatomic potential parameters used for dopant in the atomistic simulations of $\mathrm{Li}_{2} \mathrm{ZrO}_{3}$.

Author Contributions: Computation, K.A.R., N.K.; Writing, N.K.; Analysis, P.I.; Editing, A.C. All authors have read and agreed to the published version of the manuscript.

Funding: This computational work was financially supported by European Union's H2020 Programme under Grant Agreement no 824072-HARVESTORE.

Institutional Review Board Statement: Not applicable.

Informed Consent Statement: Not applicable.

Data Availability Statement: Not applicable.

Acknowledgments: Imperial College London and the Department of Chemistry, University of Jaffna, Srilanka are acknowledged for providing high performance computing facilities.

Conflicts of Interest: The authors declare no conflict of interest. 


\section{References}

1. Dong, Y.; Zhao, Y.; Duan, H.; Huang, J. Electrochemical performance and lithium-ion insertion/extraction mechanism studies of the novel $\mathrm{Li}_{2} \mathrm{ZrO}_{3}$ anode materials. Electrochim. Acta 2015, 161, 219-225. [CrossRef]

2. Thackeray, M.M.; Johnson, C.S.; Kim, J.S.; Lauzze, K.C.; Vaughey, J.T.; Dietz, N.; Abraham, D.; Hackney, S.; Zeltner, W.; Anderson, M. $\mathrm{ZrO}_{2}$ - and $\mathrm{Li}_{2} \mathrm{ZrO}_{3}$-stabilized spinel and layered electrodes for lithium batteries. Electrochem. Commun. 2003, 5, 752-758. [CrossRef]

3. Zhang, X.; Sun, S.; Wu, Q.; Wan, N.; Pan, D.; Bai, Y. Improved electrochemical and thermal performances of layered $\mathrm{Li}\left[\mathrm{Li}_{0.2} \mathrm{Ni}_{0.17} \mathrm{Co}_{0.07} \mathrm{Mn}_{0.56}\right] \mathrm{O}_{2}$ via $\mathrm{Li}_{2} \mathrm{ZrO}_{3}$ surface modification. J. Power Sources 2015, 282, 378-384. [CrossRef]

4. Kanazawa, T.; Nishikawa, M.; Yamasaki, H.; Katayama, K.; Kashimura, H.; Hanada, T.; Fukada, S. Study on Tritium Release Behavior from $\mathrm{Li}_{2} \mathrm{ZrO}_{3}$. Fusion Sci. Technol. 2011, 60, 1167-1170. [CrossRef]

5. Hollenberg, G.W. Fast neutron irradiation results on $\mathrm{Li}_{2} \mathrm{O}, \mathrm{Li}_{4} \mathrm{SiO}_{4}, \mathrm{Li}_{2} \mathrm{ZrO}_{3}$ and $\mathrm{LiAlO}_{2}$. J. Nucl. Mater. 1984, 123, 896-900. [CrossRef]

6. Kawamura, Y.; Enoeda, M.; Okuno, K. Isotope exchange reaction in $\mathrm{Li}_{2} \mathrm{ZrO}_{3}$ packed bed. Fusion Eng. Des. 1998, 39, 713-721. [CrossRef]

7. Wang, C.; Dou, B.; Song, Y.; Chen, H.; Xu, Y.; Xie, B. High Temperature $\mathrm{CO}_{2}$ Sorption on $\mathrm{Li}_{2} \mathrm{ZrO}_{3}$ Based Sorbents. Ind. Eng. Chem. Res. 2014, 53, 12744-12752. [CrossRef]

8. Peltzer, D.; Mùnera, J.; Cornaglia, L.; Strumendo, M. Characterization of potassium doped $\mathrm{Li}_{2} \mathrm{ZrO}_{3}$ based $\mathrm{CO}_{2}$ sorbents: Stability properties and $\mathrm{CO}_{2}$ desorption kinetics. Chem. Eng. J. 2018, 336, 1-11. [CrossRef]

9. Zhang, Y.; Gao, Y.; Pfeiffer, H.; Louis, B.; Sun, L.; O’Hare, D.; Wang, Q. Recent advances in lithium containing ceramic based sorbents for high-temperature $\mathrm{CO}_{2}$ capture. J. Mater. Chem. A 2019, 7, 7962-8005. [CrossRef]

10. Baklanova, Y.V.; Arapova, I.Y.; Buzlukov, A.L.; Gerashenko, A.P.; Verkhovskii, S.V.; Mikhalev, K.N.; Denisova, T.; Shein, I.; Maksimova, L. Localization of vacancies and mobility of lithium ions in $\mathrm{Li}_{2} \mathrm{ZrO}_{3}$ as obtained by ${ }^{6,7} \mathrm{Li}$ NMR. J. Solid State Chem. 2013, 208, 43-49. [CrossRef]

11. Xu, Y.; Liu, Y.; Lu, Z.; Wang, H.; Sun, D.; Yang, G. The preparation and role of $\mathrm{Li}_{2} \mathrm{ZrO}_{3}$ surface coating $\mathrm{LiNi}_{0.5} \mathrm{Co}_{0.2} \mathrm{Mn}_{0.3} \mathrm{O}_{2}$ as cathode for lithium-ion batteries. Appl. Surf. Sci. 2016, 361, 150-156. [CrossRef]

12. Ferreira, A.R.; Reuter, K.; Scheurer, C. DFT simulations of ${ }^{7} \mathrm{Li}$ solid state NMR spectral parameters and $\mathrm{Li}^{+}$ion migration barriers in $\mathrm{Li}_{2} \mathrm{ZrO}_{3}$. RSC Adv. 2016, 6, 41015-41024. [CrossRef]

13. Alexopoulos, K.; Varotsos, P. Calculation of diffusion coefficients at any temperature and pressure from a single measurement. II. Heterodiffusion. Phys. Rev. B 1981, 24, 3606-3609. [CrossRef]

14. Varotsos, P.; Alexopoulos, K. Thermodynamics of Point Defects and their Relation with the Bulk Properties; Elsevier: Amsterdam, North-Holland, The Netherlands, 1986.

15. Rupasov, D.; Chroneos, A.; Parfitt, D.; Kilner, J.A.; Grimes, R.W.; Istomin, S.Y.; Antipov, E.V. Oxygen diffusion in $\mathrm{Sr}_{0.75} \mathrm{Y}_{0.25} \mathrm{CoO}_{2.625}$ : A molecular dynamics study. Phys. Rev. B 2009, 79, 172102. [CrossRef]

16. Kordatos, A.; Christopoulos, S.R.G.; Kelaidis, N.; Chroneos, A. Defect processes in $\mathrm{Li}_{2} \mathrm{ZrO}_{3}$ : Insights from atomistic modelling. J. Mater. Sci. Mater. Electron. 2017, 28, 11789-11793. [CrossRef]

17. Gale, J.D. GULP: A computer program for the symmetry-adapted simulation of solids. J. Chem. Soc. Faraday Trans. 1997, 93, 629-637. [CrossRef]

18. Fisher, C.A.J.; Kuganathan, N.; Islam, M.S. Defect chemistry and lithium-ion migration in polymorphs of the cathode material $\mathrm{Li}_{2} \mathrm{MnSiO}_{4}$. J. Mater. Chem. A 2013, 1, 4207-4214. [CrossRef]

19. Minervini, L.; Grimes, R.W.; Sickafus, K.E. Disorder in Pyrochlore Oxides. J. Am. Ceram. Soc. 2000, 83, 1873-1878. [CrossRef]

20. Cherry, M.; Islam, M.S.; Catlow, C.R.A. Oxygen Ion Migration in Perovskite-Type Oxides. J. Solid State Chem. 1995, 118, 125-132. [CrossRef]

21. Mott, N.F.; Littleton, M.J. Conduction in polar crystals. I. Electrolytic conduction in solid salts. Trans. Faraday Soc. 1938, 34, 485-499. [CrossRef]

22. Kuganathan, N.; Ganeshalingam, S.; Chroneos, A. Defects, Diffusion, and Dopants in $\mathrm{Li}_{2} \mathrm{Ti}_{6} \mathrm{O}_{13}$ : Atomistic Simulation Study. Materials 2019, 12, 2851. [CrossRef]

23. Kuganathan, N.; Kordatos, A.; Anurakavan, S.; Iyngaran, P.; Chroneos, A. $\mathrm{Li}_{3} \mathrm{SbO}_{4}$ lithium-ion battery material: Defects, lithium ion diffusion and tetravalent dopants. Mater. Chem. Phys. 2019, 225, 34-41. [CrossRef]

24. Kuganathan, N.; Kordatos, A.; Kelaidis, N.; Chroneos, A. Defects, Lithium Mobility and Tetravalent Dopants in the $\mathrm{Li}_{3} \mathrm{NbO}_{4}$ Cathode Material. Sci. Rep. 2019, 9, 2192. [CrossRef]

25. Kresse, G.; Furthmüller, J. Efficient iterative schemes for ab initio total-energy calculations using a plane-wave basis set. Phys. Rev. B 1996, 54, 11169-11186. [CrossRef]

26. Blöchl, P.E. Projector augmented-wave method. Phys. Rev. B 1994, 50, 17953-17979. [CrossRef]

27. Monkhorst, H.J.; Pack, J.D. Special points for Brillouin-zone integrations. Phys. Rev. B 1976, 13, 5188-5192. [CrossRef]

28. Perdew, J.P.; Burke, K.; Ernzerhof, M. Generalized Gradient Approximation Made Simple. Phys. Rev. Lett. 1996, 77, 3865-3868. [CrossRef]

29. Press, W.H.; Teukolsky, S.A.; Vetterling, W.T.; Flannery, B.P. Numerical Recipes in C: The Art of Scientific Computing, 2nd ed.; Cambridge University Press: Cambridge, UK, 1992. 
30. Grimme, S.; Antony, J.; Ehrlich, S.; Krieg, H. A consistent and accurate ab initio parametrization of density functional dispersion correction (DFT-D) for the 94 elements H-Pu. J. Chem. Phys. 2010, 132, 154104. [CrossRef]

31. Heiba, Z.K.; El-Sayed, K. Structural and anisotropic thermal expansion correlation of $\mathrm{Li}_{2} \mathrm{ZrO}_{3}$ at different temperatures. J. Appl. Crystallogr. 2002, 35, 634-636. [CrossRef]

32. Oberkampf, W.L.; Barone, M.F. Measures of agreement between computation and experiment: Validation metrics. J. Comput. Phys. 2006, 217, 5-36. [CrossRef]

33. Kröger, F.A.; Vink, H.J. Relations between the Concentrations of Imperfections in Crystalline Solids. In Solid State Physics; Seitz, F., Turnbull, D., Eds.; Academic Press: New York, NY, USA, 1956; Volume 3, pp. 307-435.

34. Armstrong, A.R.; Kuganathan, N.; Islam, M.S.; Bruce, P.G. Structure and Lithium Transport Pathways in $\mathrm{Li}_{2} \mathrm{FeSiO}_{4}$ Cathodes for Lithium Batteries. J. Am. Chem. Soc. 2011, 133, 13031-13035. [CrossRef] [PubMed]

35. Nytén, A.; Kamali, S.; Häggström, L.; Gustafsson, T.; Thomas, J.O. The lithium extraction/insertion mechanism in $\mathrm{Li}_{2} \mathrm{FeSiO}_{4}$. J. Mater. Chem. 2006, 16, 2266-2272. [CrossRef]

36. Politaev, V.V.; Petrenko, A.A.; Nalbandyan, V.B.; Medvedev, B.S.; Shvetsova, E.S. Crystal structure, phase relations and electrochemical properties of monoclinic $\mathrm{Li}_{2} \mathrm{MnSiO}_{4}$. J. Solid State Chem. 2007, 180, 1045-1050. [CrossRef]

37. Pizzagalli, L. Classical Atomistic Simulations in Materials Sciences: An Introduction. Mater. Sci. 2004, 10, 125.

38. Islam, M.S.; Fisher, C.A.J. Lithium and sodium battery cathode materials: Computational insights into voltage, diffusion and nanostructural properties. Chem. Soc. Rev. 2014, 43, 185-204. [CrossRef]

39. Kuganathan, N.; Chroneos, A. $\mathrm{Na}_{3} \mathrm{~V}\left(\mathrm{PO}_{4}\right)_{2}$ cathode material for Na ion batteries: Defects, dopants and Na diffusion. Solid State Ion. 2019, 336, 75-79. [CrossRef]

40. Fisher, C.A.J.; Hart Prieto, V.M.; Islam, M.S. Lithium Battery Materials $\mathrm{LiMPO}_{4}(\mathrm{M}=\mathrm{Mn}, \mathrm{Fe}, \mathrm{Co}$, and Ni): Insights into Defect Association, Transport Mechanisms, and Doping Behavior. Chem. Mater. 2008, 20, 5907-5915. [CrossRef]

41. Gladysz, G.M.; Chawla, K.K. 2-Intrinsic voids in crystalline materials: Ideal materials and real materials. In Voids in Materials, 2nd ed.; Gladysz, G.M., Chawla, K.K., Eds.; Elsevier: Amsterdam, The Netherlands, 2021; pp. 17-39.

42. Duan, Y. Electronic structural and electrochemical properties of lithium zirconates and their capabilities of $\mathrm{CO}_{2}$ capture: A firstprinciples density-functional theory and phonon dynamics approach. J. Renew. Sustain. Energy 2011, 3, 013102. [CrossRef]

43. Henkelman, G.; Arnaldsson, A.; Jónsson, H. A fast and robust algorithm for Bader decomposition of charge density. Comput. Mater. Sci. 2006, 36, 354-360. [CrossRef] 